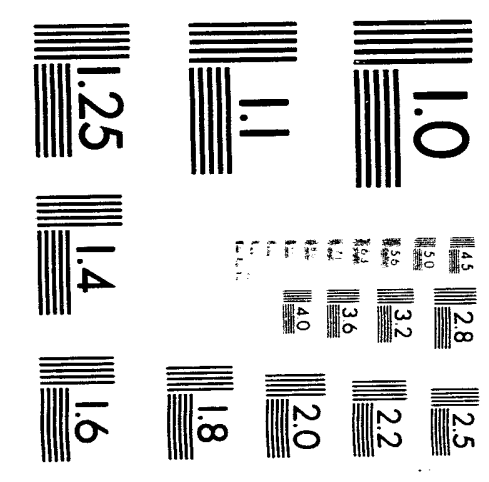



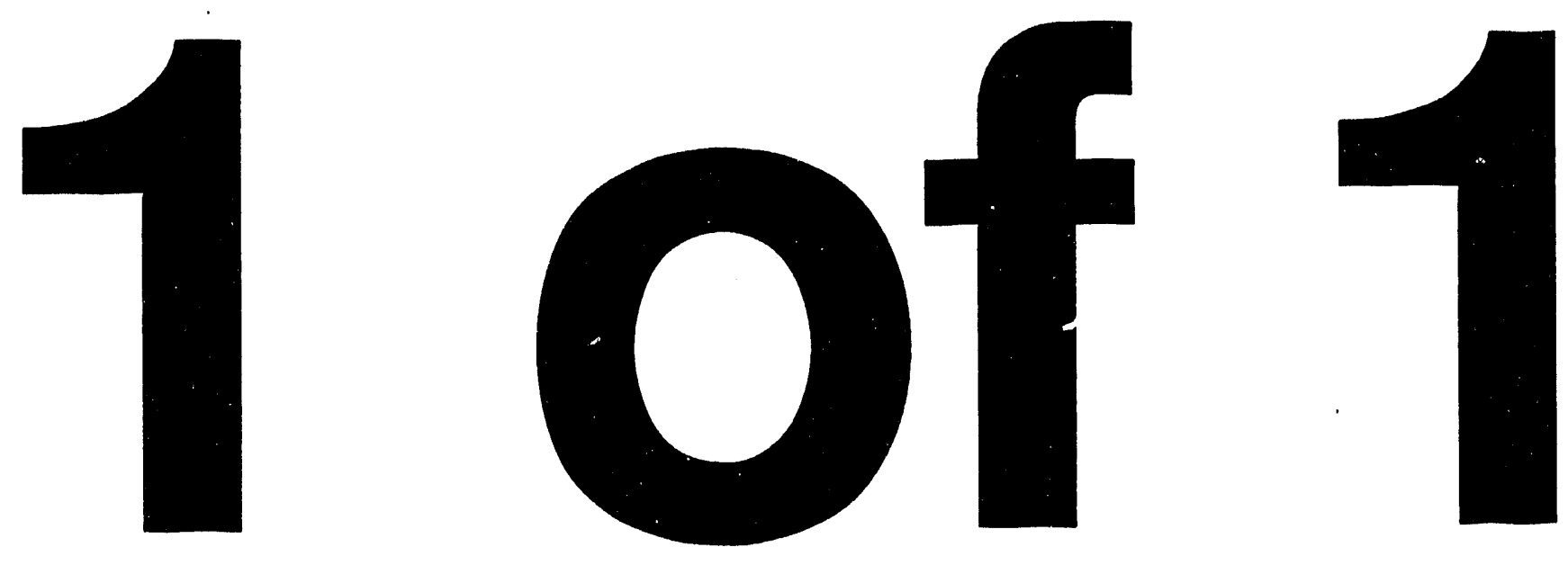
LA-UR- 93-3837
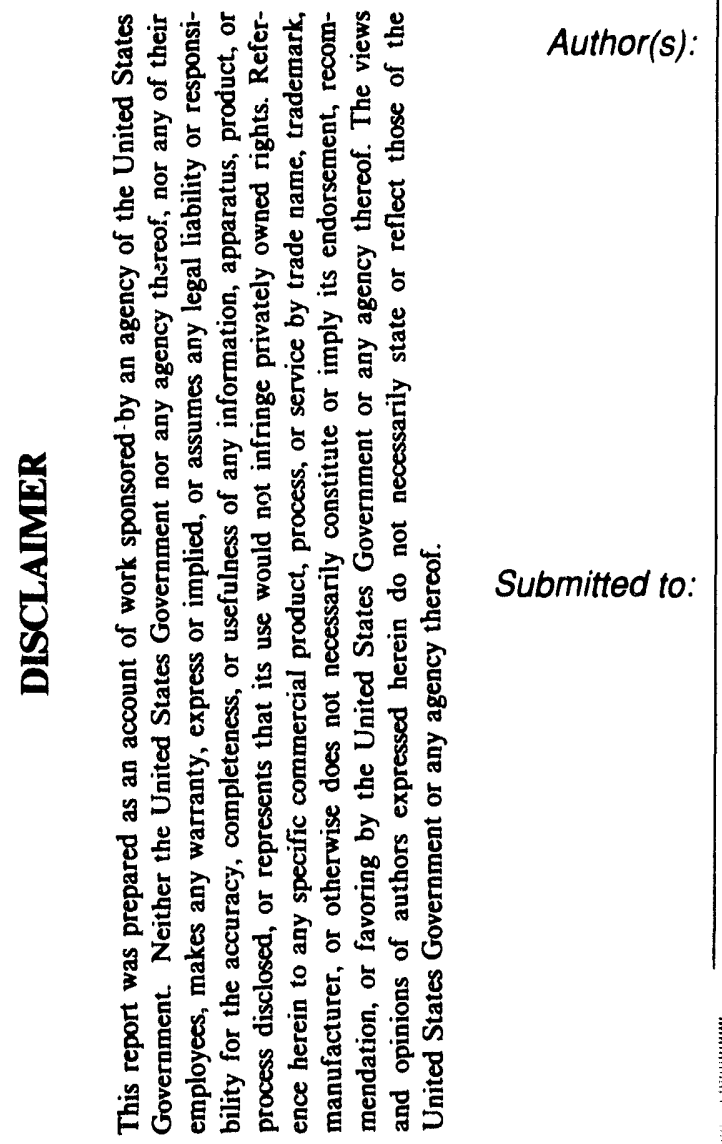

M. L. Hall, M. A. Merrigan, and R. S. Reid

Space Nuclear Power Symp.

Albuque rque, NM

January 9-13, 1994

\section{MASTER}

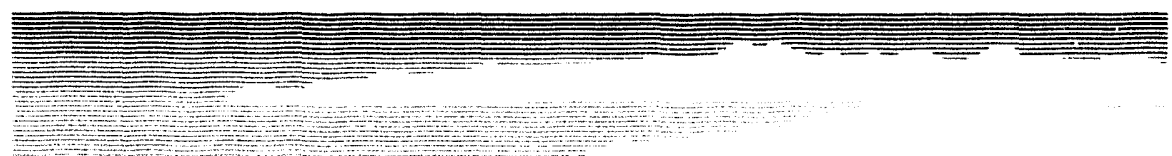

\section{Los Alamos}

NATIONAL LABORATORY

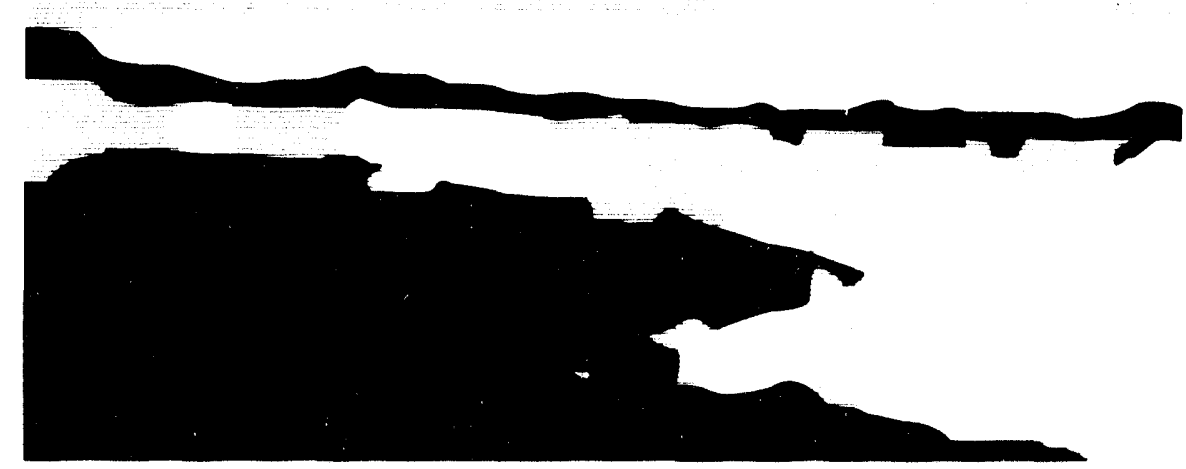

Los Alamos National Laboratory, an affirmative action/equal opportunity emplóyer, is operated by the University of California for the U.S. Department of Energy under contract W-7405-ENG-36. By acceptance of this article, the publisher recognizes that the U.S. Government retains a nonexclusive, royalty-free license to publish or reproduce the published form of this contribution, or to allow others to do so, for U.S. Government purposes. The Los Alamos National Laboratory requests that the publisher identify this article as work performed under the auspices of the U.S. Department of Energy. 


\title{
STATUS REPORT ON THE THROHPUT TRANSIENT HEAT PIPE MODELING CODE
}

\author{
Michael L. Hall \\ Los Alamos National Laboratory \\ Group N-12, MS K551 \\ P.O. Box 1663 \\ Los Alamos, NM 87545 \\ (505) 665-4312
}

\author{
Michael A. Merrigan \& Robert S. Reid \\ Los Alamos National Laboratory \\ Group MEE-13, MS J576 \\ P.O. Box 1663 \\ Los Alamos, NM 87545 \\ (505) 667-6466
}

\begin{abstract}
Improvements have been made to the THROнPUT code which models transient thermohydraulic heat pipe behavior. The original code was developed as a doctoral thesis research code by Hall. The current emphasis has been shifted from research into the numerical modeling to the development of a robust production code. Several modeling obstacles that were present in the original code have been eliminated, and several additional features have been added.
\end{abstract}

\section{INTRODUCTION}

Heat pipes are structures which transport heat by the evaporation and condensation of a working fluid, giving them a high effective thermal conductivity. Many space-based uses for heat pipes have been suggested, and high temperature heat pipes using liquid metals as working fluids are especially attractive for these purposes. These heat pipes are modeled by the THROHPUT code (THROHPUT is an acronym for Thermal Hydraulic Response Of Heat Pipes Under Transients and is pronounced like "throughput").

\section{Summary Description of THROHPUT}

The THROHPUT code provides a detailed model of the transient, thermohydraulic behavior of liquid metal heat pipes. Currently, it models only homogeneous or composite wicks in a cylindrical heat pipe structure. The boundary conditions assumed are: a time-dependent heat input in the evaporator section, zero heat transfer at the outer wall in the adiabatic section, and radiative cooling to a specified ambient temperature in the condenser section. The user specifies the dimensions of the heat pipe and of the wick structure.

The THROHPUT code models the transport and exchange of all three phases of the working fluid (solid, liquid, and gas) and of a noncondensable gas. It considers axial and radial conduction, axial and radial convection, axial and radial phase change heat transfer (both evaporation/condensation and melting/freezing) and radiative heat transfer from the condenser section. It has a geometric model for the capillary pressure difference generated by the wick. To model all of these parameters, THROHPUT solves a system which consists of fifteen partial differential equations at each axial node. The associated algebraic system consequently has a block tridiagonal matrix structure with $15 \times 15$ blocks and a set of blocks for each node. The temporal scheme used is a fully-implicit scheme which iterates on the Jacobian matrix until convergence. A sophisticated time step control scheme is utilized.

\section{RESEARCH}

\section{Tension in the Liquid}

The surface model in THROHPUT is used to develop a relationship between the liquid and the mixture gas pressure. Across a curved surface, a pressure difference exists due to the surface tension of the liquid:

$$
P_{m}-P_{l}=\frac{2 \sigma}{R_{c}},
$$

where $R_{c}$ is the radius of curvature of the surface of the liquid-vapor interface, $\sigma$ is the surface tension of the liquid, and $P$ represents the pressures of the two fluids. In THROHPUT, the radius of curvature is related 
to the amount of liquid piesent, so that the entire equation can be put in terms of system variables. For a full description of the wick surface model, see Hall (1991) or Hall (1988).

Even though THkun? is a fully-implicit model and all of its fifteen equations at each node are solved simultaneously (including the surface model), certain equations and terms within equations tend to dominate and generalizations like the following one may be made. The vapor pressure at any point is roughly equal to the saturation pressure at the wick temperature. During stariup, the wick temperature and therefore the vapor pressure are very low. In situations where the pressure difference corresponding to the amount of liquid present (according to the surface model) is greater than the vapor pressure, a negative liquid pressure would seem to be indicated. In previous THROHPUT models, this was viewed as a short-coming of the surface model, and any negative liquid pressures were set to zero during the convergence process. Consequently, if conditions were such that several adjacent axial nodes were predicted to have negative liquid pressure, then they would all have been set to zero, efficiently removing any pressure gradient that hid existed previously in the liquid. Since the pressure gradients in the liquid were eliminated, liquid return to the evaporator section became a problem. Incidentally, low, zero, or negative pressure in the liquid has little effect on the liquid density, as it is a very weak function of pressure.

Research in the area of negative liquid pressure was conducted. The concept of negative liquid pressure becomes more plausible when it is equated to tension in the liquid. Liquids do not possess shear strength, but they do possess tensile strength. The first expcriment to be conducted which exhibited tension in a liquid was carried out by the 19th-century French chemist Marcellin Berthelot (Berthelot (1850) or see Hayward (1970), Apfel (1972)). He filled a glass tube with de-aerated water and sealed it leaving a small vapor space. He then applied heat to the tube until the water expanded to fill the entire volume. Next, he allowed the tube to cool slowly, and instead of gradually forming a small bubble it remained in contact with the wetted surface. After some time, a bubble appeared all at once with an audible click. Berthelot proposed that the liquid was under tension as it cooled and he estimated that it had a negative pressure of between $-5 \times 10^{6}$ and $-3 \times 10^{6} \mathrm{~Pa}(-50$ to $-30 \mathrm{~atm})$. A similar experiment conducted by nature uses water-filled cavities in minerals. Roedder (see Apfel (1972)) has estimated pressures in these structures as low as $-1 \times 10^{8} \mathrm{~Pa}(-1000 \mathrm{~atm})$. By rotating a capillary tube filled with various liquids, Briggs (see Hayward (1970), Apfel (1972)) has generated pressures as low as $-3 \times 10^{7} \mathrm{~Pa}(-300 \mathrm{~atm})$. Another common example of tension in liquids is the the rising of sap in trees. The maximum available capillary head (without putting the liquid in tension) is equal to $10.4 \mathrm{~m}$ (34 ft), corresponding to atmospheric pressure. Since trees exist that are much taller than this, there must be negative pressure in the column that supports the sap. Scholander (see Apfel (1972)) has measured negative pressures down to $-8 \times 10^{7} \mathrm{~Pa}(-80 \mathrm{~atm})$ in trees and shrubs.

There have also been experiments more closely related to liquid metal heat pipes that have shown liquid tension. Kemme (1968) made simple calculations based on his heat pipe experiments that estimated that the liquid pressure was between -16000 and $-5300 \mathrm{~Pa}$. Anderson et al. (Anderson 1992; Anderson 1993; Anderson et al. 1993) has sustained negative pressures down to $-5000 \mathrm{~Pa}$ in Alkali Metal Thermal to Electric Converter (AMTEC) cells.

\section{Accommodation Coefficients}

Accommodation coefficients $\left(\sigma_{e}\right.$ and $\left.\sigma_{c}\right)$ are experimentally determined parameters that are used to account for less than optimal evaporation and condensation fluxes in a kinetic theory model of liquid-vapor phase change:

$$
\dot{m}=\left[2 \pi R_{g} T_{s u r}\right]^{-\frac{1}{2}}\left(\sigma_{e} P_{s a t}-\sigma_{c} P_{g}\right) .
$$

The accommodation coefficients vary from zero to one, depending on surface contamination, noncondensable gas presence, surface grazing angle, dimer content of the vapor, liquid recession into the wick, and the local flow regime (Hall and Doster 1990; Hall 1988).

An in-depth review of the literature pertaining to experimental measurement of evaporation/condensation accommodation coefficients was conducted. In particular, Niknejad and Rose (1981) contains a thorough review of the experimental work in the field, and cites most of the work referred to in Hall and Doster (1990). 
Their final conclusion was that previous investigations had yielded values of the accommodation coefficients that were less than unity because of a combination of surface contamination, noncondensable gas presence, inadequate measurement techniques, and other forms of experimental error which significantly impaired the reliability of the measurement. Their conclusion was further supported by their own experimentation, which confirmed that values of the accommodation coefficients were close to unity.

\section{MODIFICATIONS TO THROHPUT}

\section{Surface and Evaporation/Condensation Models}

One of the primary problems with early code runs had been insufficient liquid return to the evaporator section. The eventual dry-out of the evaporator section and the subsequent termination of modeling was viewed as a failure, since this condition did not occur experimentally for the same conditions. One of the methods which was employed to counteract this problem was the variation of the evaporation and condensation accommodation coefficients. There was some justification for accommodation coefficients being less than unity in the literature, and changing them would certainly affect the liquid return to the evaporator, so a search was conducted to determine if there were any combinations which produced both adequate liquid return and temperature profiles which corresponded to the experimental values. The search was largely unsuccessful: both criteria could not be satisfied simultaneously, although each could be satisfied separately (Hall and Doster 1990).

Further research into two areas yielded important information that made a significant impact on the modeling effort. First, research into experimental accommodation coefficient determination suggested that values closer to unity were appropriate for heat pipe conditions (see section entitled "Research: Accommodation Coefficients"). 'This prompted setting the coefficients to unity for all future code runs. Second, research into the possibility of liquid tension, or negative liquid pressure, produced several references which validated its physical existence (see section entitled "Research: Tension in the Liquid"). Changes were then made to the capillary pressure relationship in TuROHPUT to allow negative liquid pressure. These changes do preclude usage of the Horizontal (iravity Model (Hall 1991; Hall 1988) because the HGM assumes that no negative liquid pressure is allowed in the course of its derivation.

\section{$\underline{\text { State Routines }}$}

The original THROHPUT code was developed with only one working fluid, lithium, one wall material, molybdenum, and one noncondensable gas, air. The ease of addition of new materials and fluids is dependent upon the availability of appropriate data. Wall materials are easily added, as they only require knowledge of the thermal conductivity, the specific heat and the density, preferably all as functions of temperature. A new noncondensable gas requires nore data than a new wall material, in the form of the enthalpy, internal energy, thermal conductivity, and viscosity (all as functions of temperature). In addition, the molecular weight and critical point variables (temperature, pressure, volume) need to be known. For a new working fluid, a great deal of data is necessary, due to the need for information on each of the phases (see Table 1). Much of this data is difficult to locate, in particular the vapor properties.

The first additions to the working fluids modeled by THROHPUT were liquid metals, because liquid metals are modeled more accurately by the code due to the assumption that the thermal conductivity of the fluid is similar to that of the wick material. The working fluids that have been included in the code to date include lithium, sodium, potassium, rubidium, cesium, mercury and silver. Additional working fluids that may be added in the future include water, freons, cryogens, biphenyl, naphthalene, and other organic fluids. The wall materials that have been included in THROHPUT are molybdenum and rhenium. Wall materials proposed for future inclusion are $\mathrm{Ni}-1 \mathrm{Zr}, \mathrm{Ti}, \mathrm{Mo}-13 \mathrm{Re}, \mathrm{Mo-41Re}$, stainless steels, Ta-10W, and Al. Air ramains the only noncondensable gas included in the code. Future noncondensable gases that have been suggested include neon, argon and helium.

There are many routines in THROHPUT that form the state routine package. In addition to the properties mentioned above, inverse functions and derivative functions are needed in many cases. All of the property 
TABLE 1. Data Needed for Each Working Fluid. C denotes a constant value, $F(T)$ denotes a function of the temperature, and $\mathrm{F}(\mathrm{P})$ denotes a function of the pressure.

\begin{tabular}{|l|c|c|c|}
\hline Property & Solid & Liquid & Vapor \\
\hline \hline Density & $\mathrm{F}(\mathrm{T})$ & $\mathrm{F}(\mathrm{P}, \mathrm{T})$ & Ideal gas \\
\hline Saturation Pressure & & & $\mathrm{F}(\mathrm{T})$ \\
\hline Saturation Temperature & & & $\mathrm{F}(\mathrm{P})$ \\
\hline Internal Energy & $\mathrm{F}(\mathrm{T})$ & $\mathrm{F}(\mathrm{T})$ & $\mathrm{F}(\mathrm{T})$ \\
\hline Enthalpy & & & $\mathrm{F}(\mathrm{T})$ \\
\hline Thermal Conductivity & $\mathrm{F}(\mathrm{T})$ & $\mathrm{F}(\mathrm{T})$ & $\mathrm{F}(\mathrm{T})$ \\
\hline Sound Speed & & $\mathrm{F}(\mathrm{T})$ & \\
\hline Surface Tension & & $\mathrm{F}(\mathrm{T})$ & \\
\hline Viscosity & & $\mathrm{F}(\mathrm{T})$ & $\mathrm{F}(\mathrm{T})$ \\
\hline Adiabatic Exponent & & $\mathrm{F}(\mathrm{T})$ & \\
\hline Critical Temperature & & & $\mathrm{C}$ \\
\hline Critical Pressure & & & $\mathrm{C}$ \\
\hline Critical Volume & & & $\mathrm{C}$ \\
\hline Molecular Weight & & & $\mathrm{C}$ \\
\hline Mclting Point & $\mathrm{C}$ & & \\
\hline
\end{tabular}

information is in the form of functional evaluations; there are no table lookups. Many of the functions were derived by using least-squares regression on table values from the literature. The original turonrur code devoted approximately 900 lines to state routines; the current code contains over 6000 lines of code in the state routine packige.

\section{RESULTS}

With the aforementioned modifications to THROHPUT the observed response to heat pipe transients has been greatly improved. In particular, the liquid return to the evaporator section has been enhanced to the extent that during reasonable transients it is no longer a consideration.

THROHPUT has been used to model the transient operation of a SPAR-8 heat pipe which was fabricated and tested at Los Alamos National Laboratory (Merrigan et al. 1986). This heat pipe had an evaporator section of $(0.4 \mathrm{~m}$, an adiabatic section of $0.09 \mathrm{~m}$, and an overall length of $4.0 \mathrm{~m}$. It had an annular wick design and used lithium as a working fhuid. The initial condition was a frozen solid state at $300 \mathrm{k}$. Figure 1 shows a comparison of the experimental measurements of the external wall temperature and the model results at three different times during the transient. At $2400 \mathrm{~s}$, there is very good agreement between the experimental and calculated values. At later times, the calculated values seem to lag behind the experimental values. One cause for this behavior is that the values used for the heat input to the Turoupur code were actually the experimentally measured heat output values. Since there is a time lag between heat input and output, especially during startup, a corresponding time lag is caused by using the output values instead of the real input values. A heuristic method for dealing with this problem is currently being developed by the llall.

Figure 2(a) shows the liquid and vapor pressures at the end of the modeled transient, $13,260 \mathrm{~s}(3.68 \mathrm{hrs})$. At this time in the model, the melt front is located about halfway down the length of the heat pipe, which is in partial length operation. On the condenser side of the melt front, all of the pressures are nearly zero, as the saturation pressure is almost zero at low temperatures. On the evaporator side of the melt front, a complete heat pipe cycle is in operation, with adequate liguid return to replenish the evaporative losses. Note that the liquid pressure gradient (and consequently liquid flow) would be non-existent without the ability to put the liquid in tension. The maximum tension in the liquid obtained here is $-150 \mathrm{~Pa}$. At various times during the code run, the liquid pressure values have been calculated as low as $-10000 \mathrm{~Pa}$, well within experimental observations and theoretical predictions. 


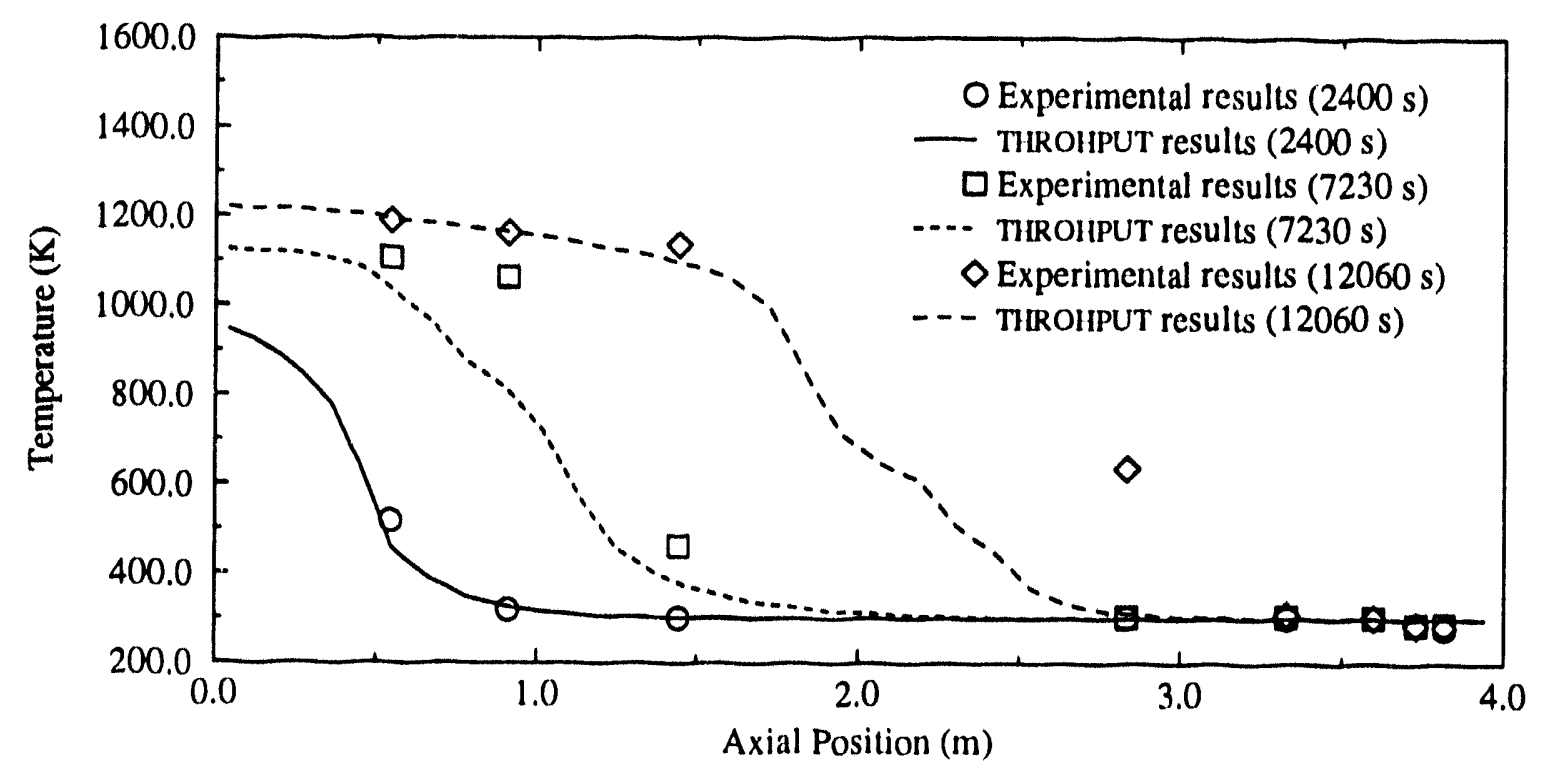

FIGURE 1. SPAR-8 Experimental Comparison to tHROHPUT Model Results at $2400 \mathrm{~s}, 7230 \mathrm{~s}$, and $12060 \mathrm{~s}$.

The velocities of the liquid (multiplied by 10,000) and the vapor at $13,260 \mathrm{~s}$ are shown in Figure 2(b). The liquid velocity is negative, representing return flow towards the evaporator section. The vapor velocity curve is typical for heat pipes, increasing roughly linearly through the evaporator section, and then decreasing through the condenser section. The liquid velocity distribution is also consistent with expectations. Assuming that there is an approximate equilibrium in the mass flow rates of the vapor and liquid leads to a velocity ratio of 53,000 , which is indeed the case.

This run used moderately fine axial noding ( 40 nodes) and modeled the first hour of the transient in $29 \mathrm{cpu}$ minutes on a Sun SPARCstation 10/41 (the entire 3.67 hour transient was modeled in 3.06 hours, giving a real to cpu-time ratio of 1.20 . There was no "tuning" of any sort done (the accommodation coefficients were set to unity).

\section{FUTURE WORK}

Future efforts will concentrate on the addition of more fluid properties, improving the input/output capabilities, and other minor refinements to the code. Additional research will be direcled into modeling alternate wick geometries, such as axial groove and arterial wick designs. The THROHPUT code will be used to examine the sensitivity of heat pipe operation to various physical phenomena, to predict heat pipe response to extreme transients, and to analyze the merit of possible design alternatives.

\section{Acknowledgments}

The research was performed at Los Alamos National Laboratory with internal funding and with funding from the Air Force's Phillips Laboratory in Albuquerque, NM. 


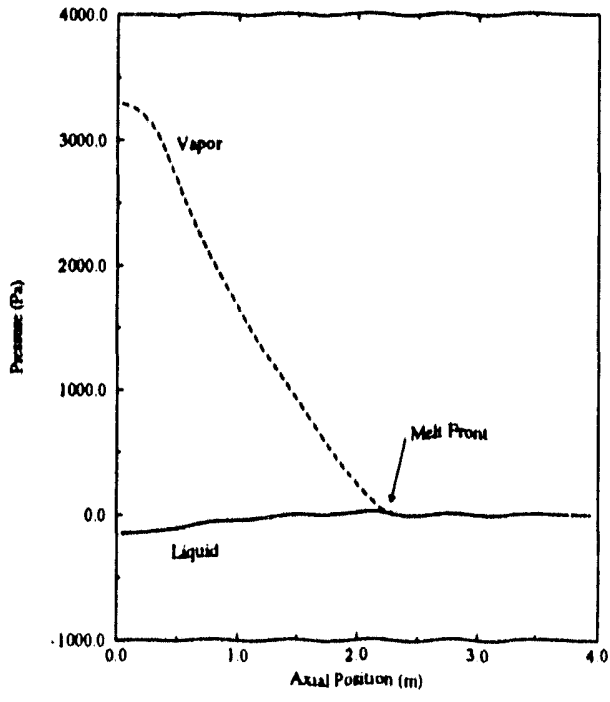

(a) Liquid and Vapor Pressure Distributions.

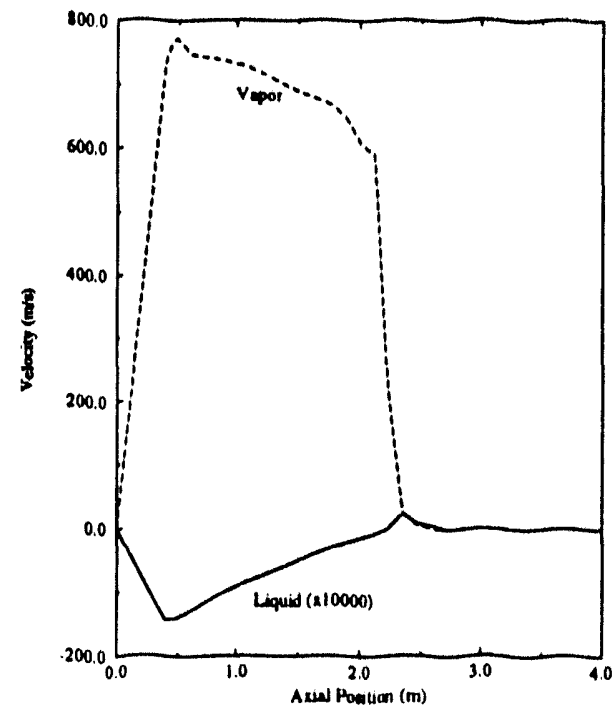

(b) Liquid and Vapor Velocity Distributions.

FIGURE 2. SPAR-8 THRoHPut Model Results at $13,260 \mathrm{~s}$

\section{References}

Anderson, Willian G. (1992) "Sodium Wick Pumping Experiments for a Vapor-Fed AMTEC System", in Proceedings of the 27th Intersociety Energy Conversion Engineering Conference, volume 3, pp. 111-116, San Diego, CA, August 3-7 1992, paper no. 929146.

Anderson, William G. (1993) "Negative Pressures in Alkalj Metal Heat Pipes", in Proceedings of the National Heat Transfer Conference, Atlanta, GA, August 8-11 1993.

Anderson, William G., Joseph J. Bland, Joseph F. Ivanenok, and Robert K. Sievers (1993) "Design of a Wick.Pumped, VaporFed AMTEC System", in Proceedings of the 28th Intersociety Energy Conversion Engineering Conference, volume 1, pp. 835-841, Atlanta, GA, A ugust 8-13 1993, paper no. 93038.

Apfel, Robert E. (1972) "The Tensile Strength of Liquids", Scientific American, pp. 58-71, December 1972.

Berthelot, Marcellin (1850) "Sur Quelques Phénomènes de Dilatatjon Forcée Des Liquides", Annales de Chimie et de Physique, 30: $232-237,1850$

Hall, Michael L. (1988) Numerical Modeling of the Transient Thermohydraulic Behavior of High Temperature Heat Pipes for Space Reactor Applications, PhD thesis, North Carolina State University, Department of Nuclear Engineering, Raleigh, NC, March 1988.

Hall, Michael L. (1991) "Wick Surface Modeling in Heat Pipes", in Transactions of the 1991 American Nuclear Society Winter Meeting, pp. 735-737, San Francisco, CA, November 10-15 1991, LA-UR-91-1208.

Hall, Michael L. and J. Michael Doster (1990) "A Sensitivity Study of the Effects of Evaporation/Condensation Accommodation Coefficients on Transient Heat Pipe Modeling", International Journal of Heat and Mass Transfer, 33(3): 465-481, March 1990.

Hayward, Alan T. J. (1970) "New Law For Liquids: Don't Snap, Stretch!", New Scientist, pp. 196-199, January 291970.

Kemme, Joseph E. (1968) "Ultimate Heat Pipe Performance", in Procedings of the Thermionic Conversion Specialist Con. ference, pp. 266-271, Framingham, MA, October 21-23 1968.

Merrigan, Michael A., Edward S. Keddy, and J. T. Sena (1986) "Transient Performance Investigation of a Space Power System Heat Pipe", in Proceedings of the AIAA/ASME Fourth Joint Thermophysics and Heat Transfer Conference, AlAA.801273, Boston, MA, June 2-4 1986, LA-UR-86-1567.

Niknejad, J, and J. W. Rose (1981) "Interphase Matter Transfer: An Experimental Study of Condensation of Mercury", Proceedings of the Royal Society of London, 378: 305-327, October 261981. 

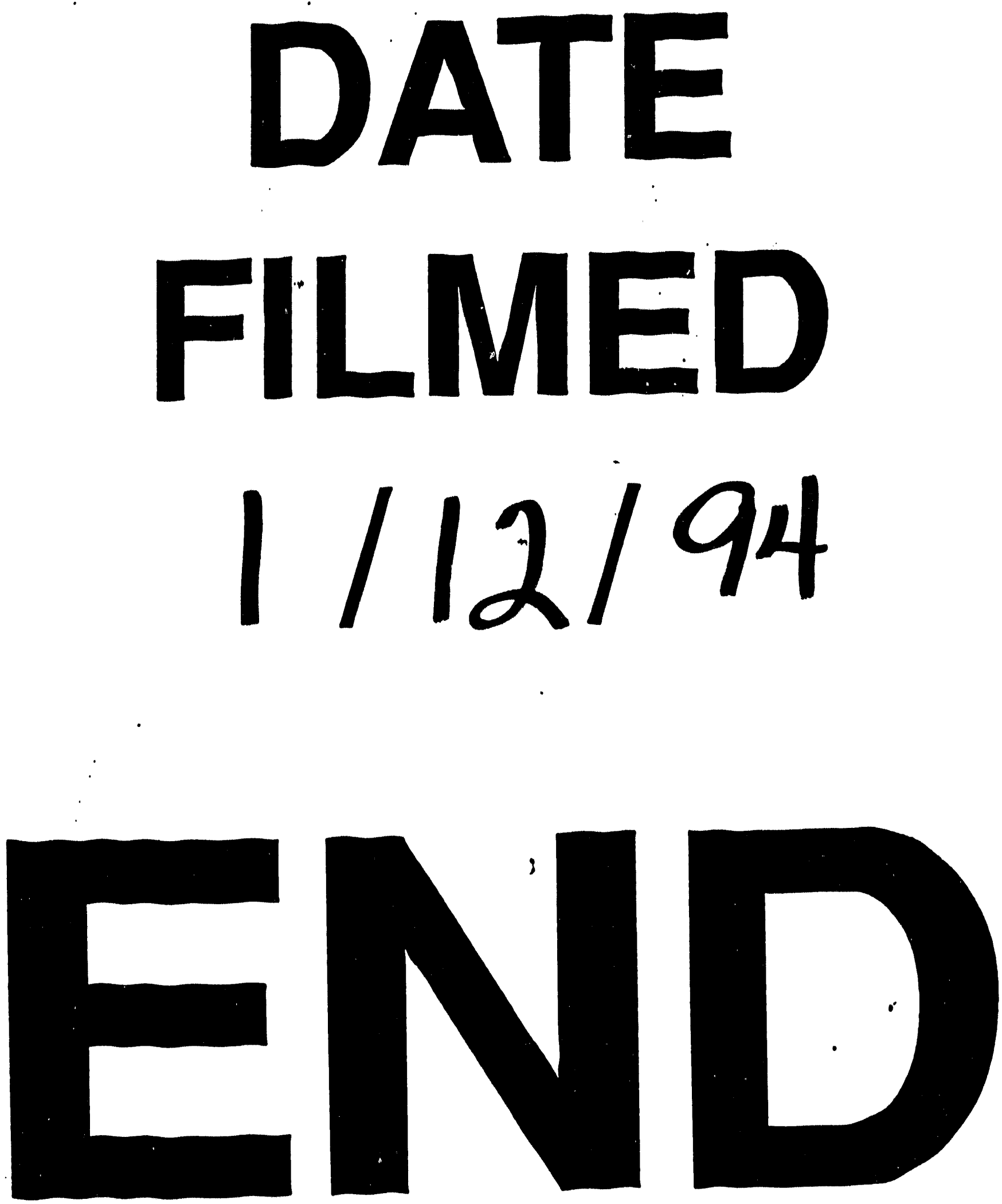
